Please quote as: Fähling, J.; Leimeister, J. M. \& Krcmar, H. (2011): Collaboration Engineering for Innovation Design Processes using the Outcome-driven approach. In: 44. Hawaii International Conference on System Sciences (HICSS) 2011, Kauai, Hawaii, USA. 


\section{Collaboration Engineering for Innovation Design Processes using the Outcome-driven approach}

\author{
Jens Fähling \\ Technische Universität München \\ Chair for Information Systems \\ Boltzmannstrasse 3 \\ 85748 Garching, Germany \\ faehling@in.tum.de
}

\author{
Jan Marco Leimeister \\ Universität Kassel \\ Chair for Information Systems \\ Nora-Platiel-Strasse 4 \\ 34127 Kassel, Germany \\ leimeister@uni-kassel.de
}

\author{
Helmut Krcmar \\ Technische Universität München \\ Chair for Information Systems \\ Boltzmannstrasse 3 \\ 85748 Garching, Germany \\ krcmar@in.tum.de
}

\begin{abstract}
For designing innovations companies need to consider both the market and technical view. Customers want to solve their individual problems, and companies need to understand these problems before they can design appropriate solutions. Consequently, this is an ongoing collaborative process including many different stakeholders. On this basis, we propose a repeatable collaboration process for designing innovations from an outcome-driven perspective. We therefore build on the seven layer model of collaboration and follow the design approach for collaboration processes. This paper describes the methodology by means of a real-world case at a company from the automotive industry. The one-day workshop at the company resulted in 565 ideas which were worked out in six project proposals, each solving a specific customer problem. Our research demonstrates that collaboration engineering can be applied to the outcome driven approach, and extends the outcome driven approach by collaboration aspects.
\end{abstract}

\section{Introduction}

Customers are not interested in products and services per se, but what they really want are solutions for their problems [20]. Customer-oriented innovations start with a customer problem which is the basis for designing solutions. This view is called the servicedominant logic [16] and requires thinking beyond the product by embracing a solutions mind-set [20]. Companies need to focus on the design of customer solutions as integrated bundles of products and services to provide customized outcomes for specific customers [22].

In many markets, such as the automobile market, existing products are adequate for most customers [20]. New features are often only a small incentive for customers to buy or upgrade to newer versions or better products. In other words, products are merely means to an end [20]. Companies will have to help customers to archive their individual goals and outcomes. They have to think beyond their products and adopt an outcome-driven mind-set.

While companies with a product mind-set start their innovation effort with the product and then find customers for the product, companies with an outcome-driven mind-set start with analyzing customers' problems [20]. Only in a second step they assemble a set of products and services to solve the problems of their customers.

But simply asking customers what they want does not give a guarantee for product success. Customers are not experts, they are not informed enough for designing solutions [23;24]. Customers can only build on their experiences and cannot imagine what they do not know about emergent technologies, new materials, or the like. Therefore, customers should rather be asked only for their desired outcomes. An outcomebased approach focuses on what customers want a new product or service to do for them.

One promising approach is to integrate customers into the innovation process in order to achieve products and services that better fit to customers' demands [6;7]. Research on lead user workshops illustrates how customers can be actively and successfully integrated in innovation processes [6;10]. A lead user is a customer who has a need before it arises for a whole market. In addition, a lead user highly profits from the satisfaction of this demand. In lead user workshops, lead users develop and elaborate concepts and solutions which help them to solve relevant problems.

However, the integration of customers also has disadvantages and dangers [23;24]. First, there is a tendency to make incremental, rather than bold, improvements that leave the field open for competitors. Second, meeting customer demands to the letter also tends to result in so-called "me-too" products, because customers often ask for missing features they have seen in similar products of other manufacturers. Third, danger arises from the common practice of listening to the recommendations of a narrow group of customers, as, for example, the lead users who were mentioned 
earlier. Finally, companies may be disappointed when they discover that their customers do not want new and improved features and functions. If they have to pay for new features, customers can even begin to resent the company.

Based on these findings, Ulwick developed an approach for capturing customer input that focuses on outcomes and not solutions. This approach gathers data that help to reveal what customers are really trying to achieve in using a product or service $[23 ; 24]$.

\section{Outcome-based integration of customers}

In the Outcome-driven approach from Ulwick [23;24], companies determine what outcomes customers want to achieve and let qualified experts not customers devise the best solutions. So, marketing and development get customer inputs they need to create solutions of significant value, instead of vague inputs from customers when they are asked for solutions. This approach brings together the market and technical view. The underlying process is illustrated in Figure 1.

In the first step, the company tries to understand their customers and identify desired outcomes. Interviews with customers and observations of customers are two possibilities to establish a better understanding of customers. In addition, trend and experience reports allow insights into customer problems and desired outcomes. This step is dominated by a market view. In the second step, the company wants to understand the desired outcomes in detail. This will be modeled as an interactive and collaborative process between technical and customeroriented experts. The results of the second step represent the solution space. This step is a combination of a market and technical view, because on the one hand the market view helps to understand the customers and their desired outcomes. On the other hand, the technical view helps to interpret and translate these desired outcomes into possible solutions. Therefore experts from both domains are necessary to work together. In the third step, experts elaborate the most promising solutions. This is a technical task, where engineers generate concepts and solutions.

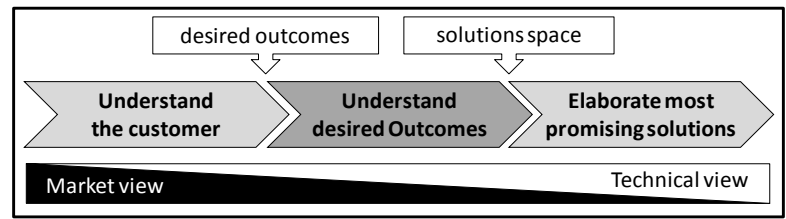

Figure 1. Outcome-driven approach. Based on [23;24]

This approach combines the world of marketing (market view) with the world of development and design (technical view). It is interesting and promising for developing innovations, but up to now there is only little research about how to manage the approach as a collaboration task. Collaboration engineering can help with designing and deploying collaboration processes for high-value and repeatable tasks.

The illustrated process of the Outcome-driven approach is used as theoretical basis for the design of the collaboration process and represents our research model (Figure 2).

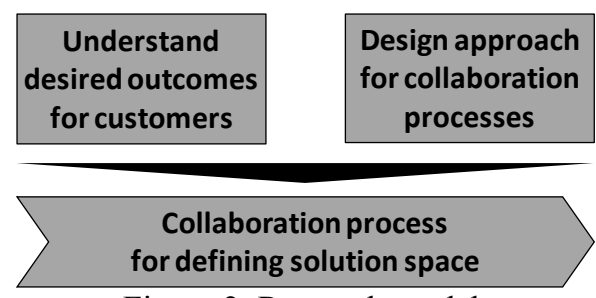

Figure 2. Research model

\section{Collaboration Engineering}

Collaboration engineering is an approach for the systematic development of transferable, reusable and predictable collaboration processes that support highvalue and recurring tasks $[2 ; 8 ; 13]$. This approach allows teams to design repeatable collaboration processes on their own, so practitioners do not need the ongoing support of collaboration professionals. Collaboration engineering can be considered as facilitation, design, and a training approach that aims to create collaboration processes that can be supported with collaboration support tools such as group support systems (GSS) [13]. These collaborative work practices can then be used by self-sustaining communities. Thus, collaboration engineering is a promising approach for supporting innovation managers with regards to the introduced Outcomedriven approach. Furthermore, the Outcome-driven approach contains several high-value and recurring tasks, such as collecting, organizing and evaluating outcomes. Therefore, collaboration engineering provides a seven layer model of collaboration that helps so-called collaboration engineers with the design and elaboration of a collaboration process. This model will be introduced in the following.

\subsection{Seven layer model of collaboration}

Figure 3 summarizes the seven layer model of collaboration [3]. The goals at the top of this model represent desired states or outcomes. This layer deals with group goals, private goals and goal congruence. Products are tangible or intangible artifacts or 
outcomes generated by the group. Activities are subtasks that, when completed, yield the products that constitute attainment of the group goal. These are activities that deal with what groups have to do in order to achieve their goals. Patterns of collaboration are observable patterns of behavior and outcomes that emerge over time in collaboration tasks. A collaboration technique is a reusable procedure for invoking useful interactions within a team working toward a group goal. Tools are artifacts or systems used in performing an operation for moving a group towards its goal. Finally, a script is everything team members say to each other and do with their tools to move toward the group goal.

Each layer is important for the design of collaboration processes, but the model gives no specific advice about how these layers may be considered, nor does it indicate how the data for each layer should be gathered. In this research we follow the design approach for collaboration engineering [12].

\begin{tabular}{|l|l|}
\hline \multirow{2}{*}{ Why } & 1. Goals \\
\cline { 2 - 2 } & 2. Products \\
\hline What & 3. Activities \\
\hline $\begin{array}{l}\text { How } \\
\text { (logical } \\
\text { design) }\end{array}$ & 4. Patterns of Collaboration \\
\cline { 2 - 2 } $\begin{array}{l}\text { How } \\
\text { (physical } \\
\text { design) }\end{array}$ & 5. Techniques \\
\cline { 2 - 2 } & 7. Scripts \\
\hline
\end{tabular}

Figure 3. Seven layer model of collaboration [3]

A critical challenge in collaboration engineering concerns the question of how the design activities have to be executed, and which design choices have to be made to create a process design [13]. Based on the theoretical foundation and insights of collaboration engineering and the seven-level model, Kolfschoten and de Vreede [12] have developed a design approach for collaboration processes, which is introduced in the next section.

\subsection{Design Approach for Collaboration Engineering}

Collaboration process design uses an approach for designing purposeful interaction within the context of a sequence of steps that helps a group to achieve its goal $[12 ; 13]$. The design approach for collaboration engineering is the result of a four-year design science study which was evaluated and improved in four trials with 37 students [12].
The design approach for collaboration engineering (Figure 4) consists of five steps. The first step contains an analysis of the collaborative task that the group has to execute. Further, the characteristics of the group and stakes involved are considered. The second step concerns the decomposition of the collaborative task into different activities. These activities can be performed using collaboration design patterns, called thinklets [2;11]. In the next step, the thinklets are matched to the decomposed activities. In the fourth step, the agenda for the collaboration process can be built. Finally, the design of the process is validated to test whether it is likely to yield the desired results.

These steps are usually not executed step-by-step, but iteratively [12]. Decisions in each step can affect decisions in former or further steps. Figure 4 illustrates the design approach for collaboration engineering.

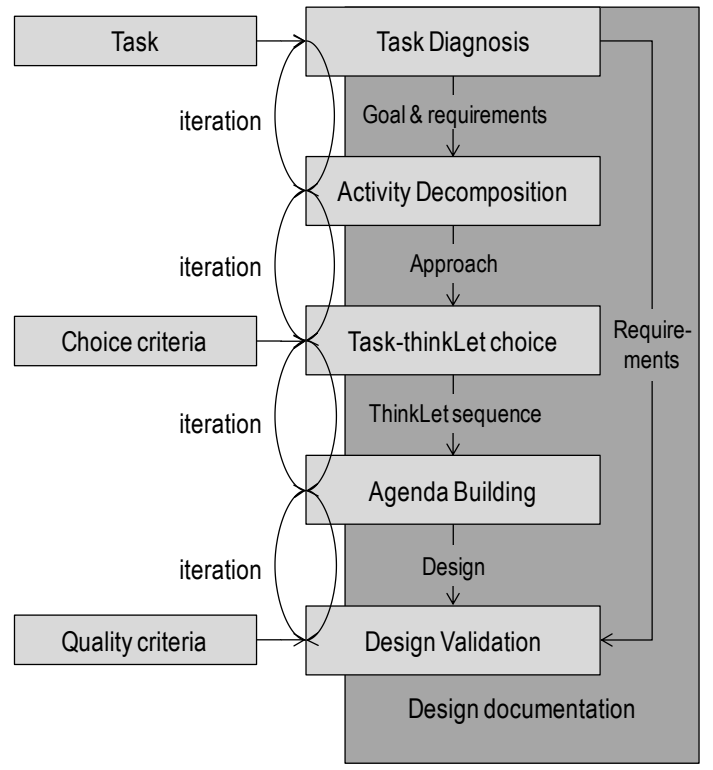

Figure 4. Design approach for collaboration engineering [12]

\section{Case Study}

This section explains how we designed the collaboration process. We thus walk through each of the five steps of the design approach, and describe and explain our decisions on the basis of the Outcomedriven approach. Although we present one step after the other in this paper, the planning process was iterative and characterized by jumps between different steps due to learning effects.

The collaboration process was designed for a company in the automotive industry. The client was a plant of this company that wanted to get fresh ideas of innovative products that would ensure sustainable 
success of the plant. In general, due to cost pressure and ongoing outsourcing activities of the company, each plant competes with other plants, and has to come up with new and innovative ideas.

This time the client did not want to hold a typical innovation workshop to find new and fresh ideas for their innovation management. The client wanted to try the Outcome-based approach.

\subsection{Task Diagnosis}

In the first step, it was important to determine, adjust and negotiate the requirements and constraints of the collaboration process [12]. We thus started with an analysis of the task, the involved stakeholders, and the facilitator and practitioner analysis.

4.1.1. Task Analysis. The task analysis concerns the definition of the collaboration process goals and deliverables, as well as the establishment of the stakeholders' commitment with respect to these goals and deliverables. According to Locke and Latham, a goal can be defined as a desired state or outcome [15].

Goal-setting theory states that a goal should be specific and challenging enough for the participants in order to evoke productivity [14]. We thus agreed on the development of ten customer-oriented ideas for a plant of the automobile manufacturer.

The deliverables represent the tangible output of the process [12]. In this case, the client agreed on the following deliverables:

- five roughly elaborated ideas that can be realized within five years, and

- five roughly elaborated ideas that can be realized in more than five years.

For the client it was very important to get suitable input for their process for project planning. That means that the client was not searching for elaborated concepts or complete solutions, but only for roughly elaborated ideas. What they were searching for, were good ideas. Hence, the client agreed on ten short presentations of roughly elaborated ideas as deliverables of the workshop.

4.1.2. Stakeholder Analysis. The purpose of this substep is to archive a deeper understanding of the group that executes the collaboration process in terms of roles, interrelationships, and individual interests.

Overall, fifteen participants were involved in the collaboration process. Each of the participants was analyzed along the following recommended questions [12]:

- What are their reasons for participation and their expectations?
- What can they contribute?

- Are they committed to the group goal?

- Will they accept the results?

- Will they accept the process?

Based on this analysis, we derived some specific design elements: 1) focus on creativity process, 2) commitment for the process at the beginning, 3) commitment for the results at the end, 4) explanation and clarification of the process at the beginning, 5) no use of mobile devices and private notebooks during the workshop, 6) transparency of the process and results no single idea and evaluation to get lost, and 7) group support systems (GSS) would be used since the participants were used to working with computers.

The stakeholder analysis revealed that we had mostly participants with engineering background. This analysis results in inviting more participants from the marketing and sales department which stayed in close contact with customers. Table 1 gives an overview of the participants of the workshop.

Table 1. Participants of the workshop

\begin{tabular}{|c|l|}
\hline Number & Role and experience \\
\hline 1 & Moderator \\
\hline 2 & Facilitator \\
\hline 2 & Organizational assistant \\
\hline 2 & Marketing experts \\
\hline 1 & Sales manager \\
\hline 5 & Executive managers \\
\hline 5 & Technical engineers \\
\hline
\end{tabular}

4.1.3. Facilitator/Practitioner Analysis. The facilitator already had considerable experience as a moderator. His technical assistant also had experience with the group support system (GSS) (Think Tank) that was used in the workshop, which helped to adjust the collaboration process. Two other facilitators had known all participants, their skills and experience, strengths and weaknesses. This knowledge helped with building teams for group work. Each group had participants with different backgrounds to maximize the heterogeneity of each group.

\subsection{Task Decomposition}

According to the constraints and requirements, the collaborative task and activities were defined. There are three possible ways to decompose the task [12]: the company already has a standardized process, an appropriate approach is described in the literature, or a new process must be described from scratch. As the client did not have a standardized process for this task, 
the process was developed on the guidelines of the Outcome-driven approach. The following activities were necessary: Identification of the most desirable outcomes for customers, appropriate solutions to serve the outcomes, and evaluation of the solutions.

4.2.1. Pattern decomposition. The aim of pattern decomposition is to determine the appropriate pattern of collaboration for each activity of the collaboration process. Overall, there are six patterns of collaboration [12;3]:

- Generate: To move from having fewer concepts to having more concepts in the set of ideas shared by the group.

- $\quad$ Reduce: To move from having many concepts to a focus on fewer ideas deemed worthy of further attention.

- Clarify: To move from less to more shared understanding of the concepts in the set of ideas shared by the group.

- Organize: To move from less to more understanding of the relationships among concepts in the set of ideas shared by the group.

- Evaluate: To move from less to more understanding of the instrumentality of the concepts in the idea set shared by the group toward attaining group and personal goals.

- Build Commitment: To move from fewer to more group members who are willing to commit to a proposal for moving the group toward attaining its goal(s).

Table 2 illustrates the mapping of activities (A1A8) and Patterns of Collaboration. The stakeholder analysis revealed that the participants of the collaboration process already know each other but have different backgrounds and experience. They also did not regularly participate in collaboration workshops. Their daily work routine was dominated by rational tasks rather than by creativity. Therefore, the collaboration process started with a short warm-up. The aim of this warm-up activity (A0) was to stimulate all participants for the creative process. This is especially important for participants to whom this is a new way of thinking, i.e., those with narrow specialties or with routine based, daily work [17]. As this step is only a warm-up before the main collaboration process, we call it step 0 and the activity A0.

In Step 1, the participants took the perspective of the customers. This step was divided into four activities (A1-A4). In A1, the participants needed to understand one specific problem of the customer. To ensure good results, it is important to concentrate on one and not different problems in parallel [23]. The participants moved from less to more shared understanding of the problems. This required a Clarify pattern. One example used was the trend of urbanization. Customers were confronted with a growing number of cars and reduced space in cities. In A2, the participants generated desirable outcomes for the customer according to the specific problem. In a brainstorming session, the participants generated various desirable outcomes that could help customers with their problem related to the trend of urbanization. One example was the distinction between a smaller car for the city and a more comfortable car for rural areas. In A3, the group organized the outcomes according to their time-to-implementation $(<5$ years and $>5$ years). Finally, in A4 the participants evaluated the ideas to identify the most promising ones. Therefore, each participant picked three individual favorite ideas. This mechanism was fast and allowed an evaluation of rough ideas without the need of a deeper understanding. This pattern resulted in a prioritized list of all outcome-based ideas.

Table 2. Pattern decomposition

\begin{tabular}{|l|l|}
\hline \multicolumn{2}{|l|}{ Activity and related Pattern of Collaboration } \\
\hline Step 0. Warm-up \\
\hline A0 & Brainstorming (Generate) \\
\hline Step 1. Identify most desirable outcomes \\
\hline A1 & $\begin{array}{l}\text { Understand the customers and their problems } \\
\text { (Clarify/Commitment) }\end{array}$ \\
\hline A2 & $\begin{array}{l}\text { Find desirable outcomes for customers } \\
\text { (Generate) }\end{array}$ \\
\hline A3 & $\begin{array}{l}\text { Organize the outcomes according to their time- } \\
\text { for-implementation (Organize) }\end{array}$ \\
\hline A4 & Prioritize the outcomes (Evaluate) \\
\hline Step 2. Find appropriate solutions to serve those \\
outcomes \\
\hline A5 & Solutions based on desired outcomes (Generate) \\
\hline Step 3. Presentation and discussion of solutions \\
\hline A6 & $\begin{array}{l}\text { Understand the solutions from a customer's } \\
\text { perspective (Clarify) }\end{array}$ \\
\hline Step 4. Evaluation of those solutions \\
\hline A7 & $\begin{array}{l}\text { Using multiple criteria for evaluation of } \\
\text { solutions (Evaluate) }\end{array}$ \\
\hline
\end{tabular}

In Step 2, the group was divided into five subgroups. Each subgroup developed solutions for one specific problem in terms of scenarios (A5). They were encouraged to use the generated ideas and combine the most promising outcomes for the customers. The group which developed solutions for urbanization, e.g., 
elaborated on a rent service for customers who owned large cars and wanted to be flexible in cities.

In Step 3, all elaborated solutions were presented (A6). The subgroups demonstrated the possibilities, strengths and weaknesses of their solutions for the customer by means of scenarios.

In Step 4, the solutions were evaluated along multiple criteria (A7).

\subsubsection{Result decomposition}

Decomposition of results should lead to a level of activities where deliverables of each activity cannot be decomposed anymore. Decomposition depends on five requirements that are defined in the first main step:

Time: the collaboration process was limited to one day. Most of the participants came from another location and would travel home on the same day. Thus, the collaboration process needed to not start before 9 a.m. and not end after 6 p.m. As a consequence, time needed to be planned efficiently towards desired results.

Project embedding: For an Outcome-driven approach, it is important to deconstruct the underlying process or activity associated with the product $[23 ; 24]$ - in this case the car. This deconstruction had to be done before the workshop especially with the help of document analysis and trend research. Each important aspect was summarized and discussed with the client in advance of the workshop in order to focus on appropriate aspects for the session. The most desirable aspects were presented by the moderator during the workshop as impulse for the brainstorming sessions.

Task complexity: Another reason for the presentations in advance of the brainstorming sessions was reducing task complexity for each participant. It was necessary to establish a common understanding across the whole group for each aspect, especially due to their different work experience and roles taken in the organization.

Technology: The moderator and facilitator already had experience with a specific group support system (GSS), named ThinkTank from GroupSystems. Therefore, the use of this GSS was planned to support some activities of the collaboration process. GSS are designed to improve the efficiency and effectiveness of collaboration processes [18;9]. The biggest advantages of GSS are anonymity, parallelism, and group memory. Anonymity allows a hierarchy-free generation of ideas, and encourages especially shy participants to participate [3]. In addition, specific participants cannot dominate the activity. Parallelism allows all participants to generate ideas at the same time, which prevents production blocking [3]. Group memory means that all ideas and votes during the process are stored electronically and can be easily used across different process steps.

Practitioner skills: The experience of the moderator and facilitator allowed for a tight agenda with different activities to be conducted.

\subsection{ThinkLet choice}

The result of the Thinklet choice is illustrated in Figure 5. For each identified activity and pattern, we chose an appropriate thinklet from [5]. Each choice is briefly explained in the following:

For warm-up we chose a FreeBrainstorm with GSS-support. For the identification of the most desirable outcomes for customers, we started with the presentation of slides, followed by another FreeBrainstorm. For organizing the brainstorming results in outcomes that can be served in five and in more than five years, we used the ThinkLet called PopcornSort. It allows a very fast organization of the generated outcomes because each item must only be moved by one participant to one of the two categories. When it is moved, it cannot be moved to the other category. The following ThinkLet called CheckMark allowed each participant to mark his or her three most promising outcomes. FreeBrainstorm, PopcornSort and CheckMark were supported by GSS which allowed a seamless information flow between the ThinkLets. Step 2 was implemented as GroupWork to provide the teams as much freedom and flexibility as possible. Each group room was equipped with a flipchart and workshop material (toolbox). After the GroupWork, the solutions were presented to all participants. For evaluation we chose the ThinkLet called MultiCriteria, which allowed each participant to evaluate the solution along three different criteria:

- Is the solution efficient?

- Is know-how already available?

- What is the potential for Unique Selling Proposition (USP)?

For each criterion we used a 5-point Likert scale: fully agree / agree / indifferent / disagree / fully disagree. 


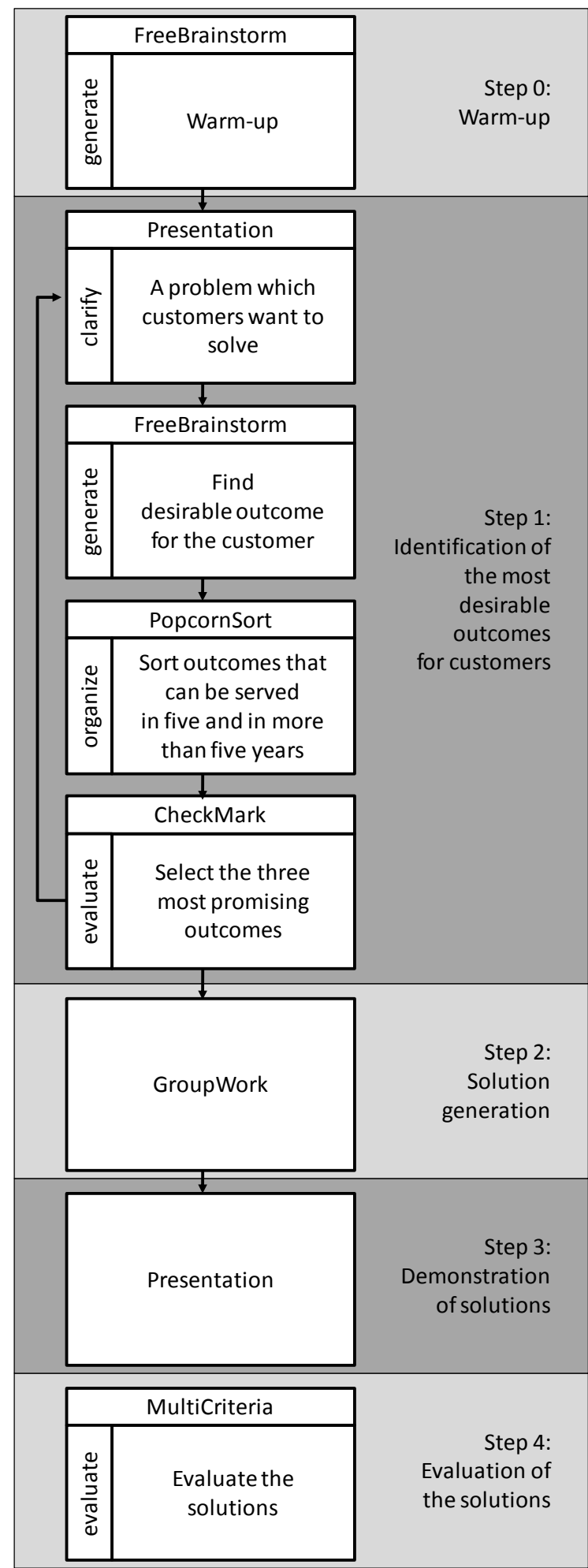

Figure 5. Entire collaboration process for the Outcome-driven approach

\subsection{Agenda building}

Table 4 on the next page illustrates the entire collaboration process for the Outcome-driven approach. The diagram follows the Agenda Design Format (ADF) that specifies all relevant information for each activity in the process including the activities, underlying questions, desired deliverables, used thinklets as well as time restrictions [8].

\subsection{Validation}

Two different aspects of the collaboration process were validated: the process by means of the Satisfaction Attainment Theory (SAT) [4] and the elaborated solutions.

Table 3 summarizes the results of the evaluation of the meeting satisfaction. We used 5-point Likert questions ( $5=$ best), relating to each of the constructs of SAT [4].

Table 3. Evaluation of meeting satisfaction

\begin{tabular}{|l|r|c|}
\hline Dimension & Mean & n \\
\hline Perceived Net Goal Attainment (PGA) & 4.17 & 9 \\
\hline Satisfaction with meeting process (SP) & 4.13 & 9 \\
\hline Satisfaction with Meeting Outcome (SO) & 3.97 & 9 \\
\hline
\end{tabular}

The values for the means indicate a high satisfaction of the participants with each of the three dimensions from the Satisfaction Attainment Theory: Perceived Net Goal Attainment, Satisfaction with Meeting Outcome as well as Satisfaction with meeting process. Each construct was measured by five questions in the questionnaire. All fifteen questions can be found in the appendix A of [4].

Further, we asked the participants for grading the workshop as a whole, with 1 as the best and 6 as the worst rating. The average rating is 2.08 . 
Table 4. Agenda for the entire collaboration process

\begin{tabular}{|c|c|c|c|c|c|}
\hline & Activity & Question/Assignment & Deliverables & thinkLet (pattern) & Time \\
\hline & $\begin{array}{l}\text { Introduce the session and } \\
\text { explain the goals, program } \\
\text { and scope }\end{array}$ & & $\begin{array}{l}\text { Commitment to the goal, } \\
\text { understanding GSS, } \\
\text { knowing each other }\end{array}$ & & 9.00 \\
\hline 1 & $\begin{array}{l}\text { Understand a specific } \\
\text { customer problem }\end{array}$ & $\begin{array}{l}\text { What problems arise from urbanization } \\
\text { for our customers? }\end{array}$ & $\begin{array}{l}\text { Awareness for the customer } \\
\text { problems }\end{array}$ & \begin{tabular}{|l} 
Presentation \\
(clarify)
\end{tabular} & 10.00 \\
\hline 2 & $\begin{array}{l}\text { Brainstorm desirable } \\
\text { outcomes for customers }\end{array}$ & $\begin{array}{l}\text { What are desirable outcomes to solve } \\
\text { those problems? }\end{array}$ & Broad list of outcomes & $\begin{array}{l}\text { FreeBrainstorm } \\
\text { (generate) } \\
\text { GSS-support }\end{array}$ & 10.20 \\
\hline 3 & $\begin{array}{l}\text { Organize the brainstorm } \\
\text { results }\end{array}$ & $\begin{array}{l}\text { Which of the generated outcomes can be } \\
\text { served within the next five years, and } \\
\text { which not? }\end{array}$ & Sorted list of outcomes & $\begin{array}{l}\text { PopcornSort } \\
\text { (organize) } \\
\text { GSS-support }\end{array}$ & 10.40 \\
\hline 4 & $\begin{array}{l}\text { Select the three most } \\
\text { promising outcomes }\end{array}$ & $\begin{array}{l}\text { What are the three most promising } \\
\text { outcomes to solve these problems? }\end{array}$ & $\begin{array}{l}\text { Ranking of the outcomes based } \\
\text { on suitability }\end{array}$ & $\begin{array}{l}\text { CheckMark } \\
\text { (Evaluate) } \\
\text { GSS-support }\end{array}$ & 10.50 \\
\hline 5 & $\begin{array}{l}\text { Understand a specific } \\
\text { customer problem }\end{array}$ & $\begin{array}{l}\text { What problems arise from the } \\
\text { demographic change for our customers? }\end{array}$ & $\begin{array}{l}\text { Awareness of the customer } \\
\text { problems }\end{array}$ & $\begin{array}{l}\text { Presentation } \\
\text { (clarify) }\end{array}$ & 11.00 \\
\hline 6 & $\begin{array}{l}\text { Brainstorm desirable } \\
\text { outcomes for customers }\end{array}$ & $\begin{array}{l}\text { What are desirable outcomes to solve } \\
\text { these problems? }\end{array}$ & Broad list of outcomes & $\begin{array}{l}\text { FreeBrainstorm } \\
\text { (generate) } \\
\text { GSS-support } \\
\end{array}$ & 11.20 \\
\hline 7 & $\begin{array}{l}\text { Organize the brainstorm } \\
\text { results }\end{array}$ & $\begin{array}{l}\text { Which of the generated outcomes can be } \\
\text { served within the next five years, which } \\
\text { not? }\end{array}$ & Sorted list of outcomes & $\begin{array}{l}\text { PopcornSort } \\
\text { (organize) } \\
\text { GSS-support }\end{array}$ & 11.40 \\
\hline 8 & $\begin{array}{l}\text { Select the three most } \\
\text { promising outcomes }\end{array}$ & $\begin{array}{l}\text { What are the three most promising } \\
\text { outcomes to solve these problems? }\end{array}$ & $\begin{array}{l}\text { Ranking of the outcomes based } \\
\text { on suitability }\end{array}$ & $\begin{array}{l}\text { CheckMark } \\
\text { (Evaluate) } \\
\text { GSS-support } \\
\end{array}$ & 11.50 \\
\hline & \multicolumn{4}{|c|}{ Break } & 12.00 \\
\hline 9 & $\begin{array}{l}\text { Understand a specific } \\
\text { customer problem }\end{array}$ & $\begin{array}{l}\text { What problems arise for our customers } \\
\text { from E-Mobility? }\end{array}$ & $\begin{array}{l}\text { Awareness of the customer } \\
\text { problems }\end{array}$ & \begin{tabular}{|l|}
$\begin{array}{l}\text { Presentation } \\
\text { (clarify) }\end{array}$ \\
\end{tabular} & 13.00 \\
\hline 10 & $\begin{array}{l}\text { Brainstorm desirable } \\
\text { outcomes for customers }\end{array}$ & $\begin{array}{l}\text { What are desirable outcomes to solve } \\
\text { those problems? }\end{array}$ & Broad list of outcomes & $\begin{array}{l}\text { FreeBrainstorm } \\
\text { (generate) } \\
\text { GSS-support } \\
\end{array}$ & 13.20 \\
\hline 11 & $\begin{array}{l}\text { Organize the brainstorm } \\
\text { results }\end{array}$ & $\begin{array}{l}\text { Which of the generated outcomes can be } \\
\text { served within the next five years, and } \\
\text { which not? }\end{array}$ & Sorted list of outcomes & $\begin{array}{l}\text { PopcornSort } \\
\text { (organize) } \\
\text { GSS-support }\end{array}$ & 13.40 \\
\hline 12 & $\begin{array}{l}\text { Select the three most } \\
\text { promising outcomes }\end{array}$ & $\begin{array}{l}\text { What are the three most promising } \\
\text { outcomes to solve these problems? }\end{array}$ & $\begin{array}{l}\text { Ranking of the outcomes based } \\
\text { on suitability }\end{array}$ & $\begin{array}{l}\text { CheckMark } \\
\text { (Evaluate) } \\
\text { GSS-support }\end{array}$ & 13.50 \\
\hline & \multicolumn{4}{|c|}{ Change location from GSS-equipped room to subgroup work rooms } & 14.00 \\
\hline 13 & Generate solutions & $\begin{array}{l}\text { What do two solutions look like that help } \\
\text { customers to achieve desired outsomes? }\end{array}$ & $\begin{array}{l}\text { Two solutions for one customer } \\
\text { problem from each group }\end{array}$ & Group Work & 14.30 \\
\hline 14 & \multicolumn{4}{|c|}{ Presentation of the solutions in the whole group } & 16.00 \\
\hline 15 & Evaluate solutions & $\begin{array}{l}\text { Please evaluate the solutions: } \\
\text { - Is the solution efficient? } \\
\text { - Is know-how already available? } \\
\text { - What is the potential for Unique Selling } \\
\text { Proposition? }\end{array}$ & $\begin{array}{l}\text { Evaluation results for each } \\
\text { presented solution }\end{array}$ & $\begin{array}{l}\text { MultiCriteria } \\
\text { GSS-support }\end{array}$ & 17.30 \\
\hline
\end{tabular}


Finally, Table 5 summarizes the evaluation results of all roughly elaborated ideas generated during the workshop. Again, we used 5-point Likert questions for the evaluation of each solution ( $5=$ best $)$.

Table 5. Evaluation of the solutions

\begin{tabular}{|c|c|c|c|c|c|c|c|}
\hline & \multirow{2}{*}{$y^{e^{0^{5}}}$} & \multicolumn{2}{|c|}{ Profitability } & \multicolumn{2}{|c|}{ Compatibility } & \multicolumn{2}{|c|}{ USP* $^{*}$} \\
\hline & & mean & st.dev. & mean & \begin{tabular}{|l|} 
st.dev. \\
\end{tabular} & mean & st.dev. \\
\hline \multirow{2}{*}{$\begin{array}{l}\text { Demographical } \\
\text { change }\end{array}$} & $<5$ & 2,500 & 1,732 & 3,750 & 1,215 & 3,583 & 1,084 \\
\hline & $>5$ & 2,667 & 1,775 & 3,333 & 1,614 & 3,000 & 1,477 \\
\hline \multirow{2}{*}{ Urbanization } & $<5$ & 3,250 & 1,545 & 3,917 & 0,996 & 3,917 & 0,793 \\
\hline & $>5$ & 3,083 & 1,782 & 3,417 & 0,996 & 3,667 & 0,492 \\
\hline \multirow{2}{*}{ e-mobility } & $<5$ & 3,000 & 1,477 & 3,750 & 0,622 & 3,500 & 0,674 \\
\hline & $>5$ & 2,833 & 1,267 & 3,083 & 0,793 & 4,250 & 0,866 \\
\hline
\end{tabular}

\section{Conclusion and discussion}

Main purpose of this paper was the development of a collaboration process for the Outcome-driven approach, and the evaluation of the process in practice. The Outcome-driven approach focuses on understanding and solving customer problems instead of just adding new features to products. It allows a development of innovation scenarios from both a market and technical view. The developed collaboration process can be seen as an extension of the Outcome-driven approach because it supports companies with planning and applying of the approach.

Second, we could illustrate a successful application of the design approach for collaboration engineering. We thus started with the description of the Outcomedriven approach for the development of innovations from a customer's point of view, and then decomposed activities of the underlying collaboration process. The evaluation of the workshop indicated not only that the participants were very satisfied with the collaboration process, but also that the outcome of the collaboration process was considered to be of high quality. Further research could concentrate on the development of an approach for applying collaboration engineering to collaborative methods, such as the introduced Outcome-driven approach. Two further examples are the Quality Function Deployment (QFD), Customer Activity Cycle [25] or Scenario Planning [19]. Usually, those methods only describe the steps and results which can be expected in each step. Collaboration Engineering could support collaboration engineers with the management of collaboration tasks within those methods. In our case study, collaboration engineering extended the Outcome-driven approach by deriving patterns of collaboration, thinklets and scripts from the decomposed activities of the Outcome-driven approach. This could be an extension to the Activity decomposition (second step) of the design approach for collaboration processes [12].
Third, the presentations of customer problems in step 1, in advance of the generation, organization and evaluation of ideas, were very important and crucial for stimulating the participants. More than 4 weeks of research and preparation were invested in creating these presentations about current and future problems of the customers with cars. In order to understand the customers, we conducted interviews, observations and a series of document and trend analyses to get insights about the customers of the car manufacturer and the problems in using their cars. The presentations described problems that customers were faced with in everyday life, and so helped the participants of the workshop to put themselves in the position of their customers. Instead of innovating products on the basis of a technical view (e.g. new technologies and features), they designed appropriate solutions from a market view that will generate value for their customers. This time-consuming task of analyzing the customers and working out presentations is often underestimated. Further research could find answers for questions about what should be presented to the participants before creative tasks, and how. One promising idea is to provide different information to different participants or groups of participants. This approach could help to establish different roles with different tasks within a collaboration task. Some participants could take on the role of a critical customer, others of a euphoric customer and others of an engineer and so on. A popular example is the method of Six Thinking Hats from de Bono. The premise of this method is that the human brain thinks in a number of distinct ways which can be identified, deliberately accessed and hence planned for use in a structured way allowing one to develop strategies for thinking about particular issues [1].

Fourth, only the use of GSS allows such a tight agenda. In only eight hours, the 15 participants generated, organized and evaluated 565 ideas for three different customer problems, elaborated six solutions, presented and evaluated them. This would be almost impossible without the use of GSS. These systems could also enable the promising approach mentioned earlier, where different participants are provided with different information and take on different roles. Further research could build on existing research results in the field Group Support Systems (GSS) or Computer Supported Cooperative Work (CSCW), and develop a method for an assessment of group activities, whether they should be supported by GSS or not. In [18], e.g., many effects of GSS on group process gains and losses are summarized. They could be used as a basis for such a method for an activity assessment. 
Fifth, due to increasing time and cost pressure, it could also be interesting for companies to separate some activities out of existing methods and execute them before or after the workshop via the internet. Further research could focus on the combination of synchronous and asynchronous collaboration tasks in same place / different place settings. Which kind of activities can be executed via internet? How must they look like? What must be considered on the interfaces between synchronous and asynchronous activities or activities in a same place / different place setting?

\section{Acknowledgement}

We thank the German Research Foundation (Deutsche Forschungsgemeinschaft - DFG) for funding this project as part of the collaborative research centre 'Sonderforschungsbereich 768 - Managing cycles in innovation processes - Integrated development of product-service-systems based on technical products'.

\section{References}

[1] E. d. Bono, Six Thinking Hats: An essential approach to business management, Little, Brown \& Company, 1985.

[2] R. O. Briggs, G.-J. de Vreede and J. Nunamaker, "Collaboration Engineering with ThinkLets to Pursue Sustained Success with Group Support Systems", Journal of Management Information Systems, 19 (4) (2003), pp. 31-64.

[3] R. O. Briggs, G. Kolfschoten, G.-J. d. Vreede, C. Albrecht, D. R. Dean and S. Lukosch, A seven-layer model of collaboration: separation of concerns for designers of collaboration systems, Thirtieth International Conference on Information Systems, Phoenix, 2009.

[4] R. O. Briggs, B. A. Reinig and G.-J. de Vreede, "Meeting satisfaction for tech-supported groups: an empirical validation of a goal-attainment model ", Small Group Research, 37 (2006), pp. 585-611.

[5] R. O. Briggs and G. J. de Vreede, ThinkLets: Building Blocks for Concerted Collaboration, GroupSystems.com, Omaha, 2003.

[6] J. Churchill, E. v. Hippel and M. Sonnack, Lead user project handbook: A practical guide for lead user project teams, 2009.

[7] E. Dahan and J. R. Hauser, "The virtual customer", The Journal of Product Innovation Management, 19 (2002), pp. 332-353.

[8] G.-J. de Vreede, R. O. Briggs and A. P. Massey, "Collaboration Engineering: Foundations and Opportunities", Journal of the Association for Information Systems, 10 (2009), pp. 121-137.

[9] M. d. Hengst, E. v. d. Kar and J. Appelman, Designing Mobile Information Services: User Requirements Elicitation with GSS Design and Application of a Repeatable Process, 37th Hawaii International Conference on System Sciences, IEEE, Hawaii, 2004.
[10] E. v. Hippel, Democratizing innovation, The MIT Press, Cambridge, Massachusetts, 2005.

[11] G. Kolfschoten, R. O. Briggs, G.-J. de Vreede, P. H. M. Jacobs and J. H. Appelman, "A conceptual foundation of the thinkLet concept for Collaboration Engineering", International Journal of Human-Computer Studies, 64 (2006), pp. 611-621.

[12] G. L. Kolfschoten and G.-J. de Vreede, "A Design Approach for Collaboration Processes: A Multimethod Design Science Study in Collaboration Engineering", Journal of Management Information Systems 26 (2009), pp. 225-256.

[13] G. L. Kolfschoten, G.-J. de Vreede, R. O. Briggs and H. G. Sol, "Collaboration Engineerability", Group Decision Negotiation, 19 (2010), pp. 301-321.

[14] E. A. Locke and G. P. Latham, A Theory of Goal Setting and Task Performance, Prentice Hall, Englewood Cliffs, NJ, 1990.

[15] E. A. Locke and G. P. Latham, "Building a practically useful theory of goal setting and task motivation: A 35-year odyssey", American Psychologist, 57 (2002), pp. 705-717.

[16] R. F. Lusch and S. L. Vargo, Evolving to a new dominant logic for marketing, in R. F. Lusch and S. L. Vargo, eds., The Service-Dominant Logic of Marketing: Dialog, Debate, And Directions, M.E. Sharpe, New York, 2006, pp. 3-28.

[17] B. MacKay and P. McKiernan, "Creativity and dysfunction in strategic processes: The case of scenario planning", Futures, 42 (2010), pp. 271-281.

[18] J. F. Nunamaker, A. R. Dennis, J. S. Valacich, D. R. Vogel and J. F. George, "Electronic meeting systems to support group work", Communications of the ACM, 34 (1991), pp. 40-61.

[19] G. Ringland, Scenario planning: managing for the future, Wiley, Chichester, 2006.

[20] M. Sawhney, Going beyond the product: Defining, Designing, and Delivering Customer Solutions, in R. F. Lusch and S. L. Vargo, eds., The Service-Dominant Logic of Marketing: Dialog, Debate, and Directions, M E Sharpe Inc, New York, London, 2006, pp. 365-380.

[21] D. Silverstein, P. Samuel and N. Decarlo, The innovator's toolkit, John Wiley\&Sons Inc., Hoboken, New Jersey, 2009.

[22] A. R. Tan, T. C. McAloone and C. Gall, Product/Service-System development: an explorative case study in a manufacturing company, International conference on engineering design (ICED), Paris, France, 2007.

[23] A. W. Ulwick, "Turn customer input into innovation", Harvard Business Review (2002), pp. 91-97.

[24] A. W. Ulwick, What customers want: using outcomedriven innovation to create breakthrough products and services, McGraw-Hill, New York [u.a.], 2005.

[25] S. Vandermerwe, "Jumping into the customer's activity cycle: a new role for customer services in the 1990s", The Columbia Journal of World Business, Summer (1993), pp. 46-56 